\title{
Three Enemies of Circadian Rhythm: Anxiety, Sleeplessness and Pain in Patients Following Open-Heart Surgery
}

\author{
Eda Ayten Kankaya (D), Ozlem Bilik (D) \\ Dokuz Eylul University, Graduate School of Health Siences, Department of Surgical Nursing, Izmir, Turkey \\ Correspondence Author: Eda Ayten Kankaya \\ E-mail: edayten@gmail.com \\ Received: $12.06 .2018 \quad$ Accepted: 15.12 .2018
}

\begin{abstract}
Objective: This study aimed to determine the relationship between preoperative anxiety and postoperative pain and perioperative sleep quality in open-heart surgery patients.

Methods: It was a cross-sectional study. The research sample included 126 patients who underwent open-heart surgery for the first time and remained in intensive care for a maximum period of 48 hours. All patients' procedures were performed with cardiopulmonary bypass and sternotomy. Data were collected using a Patient Identification Form, developed by the researcher and used to determine patients' characteristics; the Anxiety Specific to Surgery Questionnaire (ASSQ), used to determine patients' anxiety level; the Pittsburgh Sleep Quality Index (PSQI), used to measure perioperative sleep quality, and the Numeric Pain Scale (NPS), used to determine postoperative pain levels.

Results: Open-heart surgery patients experienced moderate levels of anxiety (27.28 \pm 8.48$)$, moderate postoperative pain (4.30 \pm 2.29$)$ and poor sleep quality $(10.27 \pm 4.23)$ perioperative period. In this paper, a significant, weak, and positive correlation between ASSQ score and postoperative NPS score $(r=0.318, p<0.05)$ was found; no correlation between the ASSQ score and perioperative PSQI score was found. It was determined that $90.48 \%$ ( $n=114$ ) of patients who underwent open heart surgery had poor sleep quality and there was no relation between preoperative anxiety and postoperative sleep quality.

Conclusion: The authors concluded that preoperative anxiety impacts postoperative pain but has no effect on sleep quality for open-heart surgery patients in Turkish people.
\end{abstract}

Keywords: Heart surgery, nursing, pain, sleep, anxiety

\section{INTRODUCTION}

Currently, open-heart surgery (OHS) has a wide range of interventional uses for several cardiac diseases. Despite its ability to increase length of life and quality of life, OHS remains a significant source of anxiety. Anxiety is a reaction to the body's stressors; mild anxiety is associated with increased alertness and complete rational thinking, while moderate anxiety is associated with mouth instability, palpitations, increased respiratory rate, increased heart rate, muscle tension, and intentional activity $(1,2)$. The anxiety experienced by cardiac surgery patients may have several causes. Uncertainty over the date of the surgery is an important cause of anxiety in prospective OHS patients and previous studies show how postoperative patients' anxiety is reduced (3-5) as patients may experience anxiety due to a fear of death and pain (5). Some studies have reported a fear of death before surgery was greater than the fear of death during surgery $(3,6)$.

Anxiety has a variety of outcomes including pain, increased use of analgesics, sleeplessness, surgical complications and higher mortality rates (7-9). Additionally, anxiety can lead to hypertension and thereby impair circadian rhythm and can lead to hypertension (10), with some studies reporting higher postoperative pain levels and increased use of analgesic drugs due to anxiety $(8,9)$. One study $(n=180)$ examined the impact of preoperative anxiety and educational level on mortality over a ten-year period, concluding that preoperative anxiety was associated with mortality (11). In another study (2011), the relationship between pre - and postoperative anxiety and anxiety and quality of life was investigated among Coronary Artery Bypass Grafting (CABG) patients $(n=187)$, a positive correlation was found between preoperative and postoperative anxiety $(p=0.000)$ between the two groups (12).

Acute postoperative pain following OHS is one of the most severe discomfort-inducing postsurgical conditions; OHS patients may experience pain due to sternotomy, intercostal drain, and vein or artery graft removal. Pain leads to adrenalin secretion, arteriole construction, increased after-load, and decreased cardiac output resulting from tension. Acute postoperative pain is one of the most disturbing complaints resulting from $\mathrm{OHS}$, and is associated with a risk of negative postsurgical conditions $(13,14)$. Uncontrolled pain can lead 
to postponed wound recovery, depression and chronic pain (15-17), as well as to the development of complications such as atelectasis, pneumonia and deep vein thrombosis which may affect postoperative coughing deep breathing exercises and mobilization (13). One study ( $n=371)$ found that $85 \%$ of patients experienced moderate-to-severe pain from (numerical pain score $\geq 4 / 10$ ) within the first four days, with $70 \%$ of the patients experiencing pain from sternotomy wounds (18). Other studies have shown that patients generally experienced the most pain from coughing and deep breathing $(19,20)$. While pain score was found 5.3 , after coughing it was found to be 6.6 as measured by Numeric Pain Scale (0-10).

One of the postoperative effects of preoperative anxiety experienced in patients who have undergone OHS concerns sleep quality. Sleep is a condition wherein an organism's bodily reactions and behavioral activity slow down; as its central nervous system and body passes assume a passive resting state. Conversely the brain remains active during sleep, undertaking neurophysiological recovery and depositing what it has learned while it was awake. Rest, like recovery, is a necessary condition for the body's physical and mental functions (21). OHS can impact a patient's sleep in two ways; the length of the surgical procedure can affect the patient's sleep quality, while the anxiety experienced before the surgery can disrupt the patient's circadian rhythm and causes problems in the patient's sleep-wake cycle (7). This may be risky for patients undergoing OHS as sleeplessness negatively affects cardiac function and delay patient recover times (22). Additional factors such as pain, applied procedures, and clinical environment characteristics can cause sleeplessness during the postoperative period. Several studies have reported sleep problems in OHS patients both before and after surgery pre - and postoperative period $(23,25)$.

Patients who undergo OHS remain in intensive care units (ICU) for at least one night following the procedure. The intensive care setting patients' sleep wakefulness by disturbing their circadian rhythm. Lighting, patient care activities, monitor alarms, and other, patient related-factors contribute to this situation. The natural environment of the patients is deteriorating (26-28). One study showed how many patients within ICU experienced sleeping disorders and disrupted circadian rhythms (29). Elliott, Rai, and McKinley (2014) used polysomnography to determine sleep quality over a 24-hour period, reporting that patients $(n=43)$ experienced sleeplessness due to noise, light and nursing interventions in their ICU (30). A further study reported that sleep duration on the 3rd night and the 4th night following surgery, patient's sleeping quality decreased postoperatively compared to the preoperative period (31). Kamalipour et al. (2014) conducted a study on patients undergoing OHS $(n=188)$ reporting that $14.8 \%$ still experienced sleep problems three months after their surgery (32). Hedges and Redeker (2008), conducted a study on patient sleep-quality by comparing two patient groups $(n=48)$ one treated off-pump $(n=81)$ and one treated on-pump ( $n=48)$ who had undergone CABG surgery; the researchers found that sleep quality was better in the early postoperative period in the group of patients who were treated off-pump surgery in the early period (33).

If the negative effects of anxiety remain unresolved, expectations regarding faster patient recovery and better comfort will not reach the desired level. Hence this research hopes to determine the relationship, if any, between preoperative anxiety and postoperative pain and sleep quality in OHS patients (34-36). The purpose of this study is to determine the relationship between preoperative anxiety and postoperative pain and sleep quality in OHS patients.

\section{METHODS}

This was a descriptive, cross-sectional study. Data were collected after receiving Ethical Committee Approval, as well as written and oral permission from all patient participants. The research sample contained 126 first-time OHS patients who remained in intensive care for a maximum period of 48 hours. Some patients developed complications within the ICUs and hence stayed there for more than 48 hours. All patient participants could understand and converse in Turkish, received no psychiatric diagnosis and had no neurological problems, none of the patients were given sleeping pills throughout the study period. All patients were hospitalized at least one day before surgery; all procedures were performed with cardiopulmonary bypass and sternotomy. The data were collected in July and December 2015.

There are three research questions to this study:

1. What are the anxiety scores of the patient before OHS?

2. Is there any relationship between mean preoperative anxiety scores and mean postoperative pain scores for OHS patients?

3. Is there any relationship between means preoperative anxiety scores and means sleep quality index scores for OHS patients?

\subsection{Sample selection}

Calculation of the sample size was based on the study by Karancı and Dirik (2003), which described preoperative anxiety level score in emergency surgery patients. Herein, an effect size of 0.2 was accepted to be clinically significant (37). A sample size of 126 of $80 \%$ power was calculated to detect an effect size of 0.2 at a $p<0.05$ level of significance using mean of anxiety level of scores. Sample power was detected of $96 \%$ as a middle effect size using Gpower software program respectively.

\subsection{Ethics}

Both hospitals included in this study and Dokuz Eylul University's Ethics Committee granted their permission and approval (number 528). All participants provided 
informed consent before responding to the questionnaires. All information within this and its questionnaires remains confidential, and participants were informed of this before they gave consent.

\subsection{Data collection}

Data were collated using a Patient Identification Form, developed by the researcher and used to determine patients' characteristics; the Anxiety Specific to Surgery Questionnaire (ASSQ), used to determine patients' anxiety levels; the Pittsburgh Sleep Quality Index (PSQI), used to measure perioperative sleep quality, and the Numeric Pain Scale (NPS), used to determine postoperative pain levels. ASSQ data were collected 24 hours before surgery because patient anxiety levels are heightened during this period. PSQI and NPS data were evaluated during the postoperative period when the patients were brought into the service (2472 hours after surgery). Postoperative data were evaluated at the same time, in the morning, after breakfast and while nursing care was being provided to the patient.

\subsection{Measurements}

The Patient Identification Form consists of questions developed to determine the socio-demographic characteristics-such as the age, gender, education level and profession of the patient-as well as the date of their surgery, their the total number of long of stay in the hospital prior to the surgery and current comorbid diseases of patients.

The ASSQ was developed by Karancı and Dirik (2003) to evaluate intraoperative and postoperative anxiety in surgical patients. This questionnaire consists of 10 questions with responses given per a five-point Likert scale (from "1: I disagree completely", to "5: I agree completely"). The ASSQ score is obtained by addition of the scores replies given to all the articles. The highest possible score for the questionnaire is 50. There is no a breakpoint. The original Cronbach's alpha coefficient for this questionnaire was 0.79 (37); the coefficient was calculated as 0.78 for the current study.

The NPS scale provides a numerical categorization of pain severity; the scale ranges from zero ("no pain") to 10 ("unbearable pain") (38).

The PSQI was developed by Buysse et al. (39); a validity and reliability test for this questionnaire was performed by Agargün, Kara and Anlar (1996) a Turkish study (40). This is a self-report questionnaire consisted of 19 items evaluating sleep quality or sleep disorder over a month. The questionnaire was comprised of 24 questions, 19 self-report questions and five further questions that were answered by the patient's spouse or roommate.
There are seven components to 18 scored questions within the questionnaire: subjective sleep quality, duration until falling asleep, duration of sleep, habitual sleep activity, sleep disorder, use of sleep medication and daytime function disorder. These questions are answered using points ranging from $0-3$, with higher points reflecting poorer sleep quality. Each of the seven major headings were first evaluated within themselves, then added up. A total points score of five or above is regarded to reflect poor sleep quality (40).

\subsection{Statistical analysis}

Data analysis was completed using the SPSS 16.0 program. In the study, patients' ASSQ-, PSQI - and NPS-score averages were calculated according to gender using a t-test marital status social security scores were calculated using a in Mann-Whitney U test; ASSQ, PSQI and NPS score averages were calculated according to education, profession, surgical intervention and chronic diseases using a Kruskal-Wallis test. Pearson correlation analysis was used to determine the relationship between patients' ASSQ, PSQI and NPS scores.

\section{RESULTS}

$66.7 \%(n=84)$ of the patients were male. The average age of all patients is $58.81 \pm 12.17$ are male, of which $57.9 \%(n=73)$ underwent CABG. While $28.6 \%(n=36)$ of the participators had hypertension, their hospital stay was found to be $10.28 \pm 5.41$ in days.

The mean anxiety score of patients was $27.28 \pm 8.48$ (Table 1 ). Patients' mean PSQI scores were $10.27 \pm 4.23 ; 66.7 \%(n=84)$ of all patients whose mean age was $58.81 \pm 12.17$ were male, of which $57.9 \%(n=73)$ underwent CABG; $28.6 \%(n=36)$ of the participants had hypertension, while the mean hospital-stay time for all patients was $10.28 \pm 5.41$ days (Table 1 ).

A difference was detected in terms of gender in patients' ASSQ scores $(p=0.005, p<0.5)$ (Table 1$)$. The mean anxiety score of patients were significant regarding both their educational level and profession ( $p=0.008$ and $p=0.027, p<0.05)$; an advanced analysis determined this difference was caused by literate group and housewives. A difference between mean ASSQ scores were significant in having chronic diseases $(p=0.010, p<0.05)$ (Table 1). A weak and positive, statistically significant relationship between patients' mean anxiety and mean pain scores was found $(r=0.318 p<0.05)$, no statistically significant relation was found between mean anxiety score and mean sleep quality scores ( $r=0.129 \mathrm{p}>0.05$ ) (Table 2). Within the study $93.7 \%(n=118)$ of patient participants were found to have poor sleep quality (Table 3 ). 
Table 1. Investigation of Anxiety Specific to Surgery Questionnaire by Socio-Demographic -Clinical Characteristics of Patients $(n=126)$

\begin{tabular}{|c|c|c|c|c|c|c|c|}
\hline \multirow{2}{*}{\begin{tabular}{|l|} 
Socio-Demographic Characteristics \\
\end{tabular}} & \multirow[b]{2}{*}{ Number (percent) } & \multicolumn{2}{|c|}{ Anxiety Specific to Surgery } & \multicolumn{2}{|c|}{$\begin{array}{l}\text { Pittsburgh Sleep Quality } \\
\text { Index }\end{array}$} & \multicolumn{2}{|c|}{ Numeric Pain Scale } \\
\hline & & $\bar{x} \pm S D$ & $p$ & $\bar{x} \pm S D$ & $p$ & $\bar{x} \pm S D$ & $p$ \\
\hline \multicolumn{8}{|l|}{ Gender } \\
\hline Female & $42(33.3)$ & $30.35 \pm 8.56$ & \multirow{2}{*}{$0.005^{*}$} & $11.64 \pm 4.03$ & \multirow{2}{*}{$0.01^{*}$} & $4.97 \pm 2.27$ & \multirow{2}{*}{$0.021 *$} \\
\hline Male & $84(66.7)$ & $25.75 \pm 8.06$ & & $9.59 \pm 4.18$ & & $3.97 \pm 2.24$ & \\
\hline \multicolumn{8}{|l|}{ Level of Education } \\
\hline \begin{tabular}{|l|} 
Literate \\
Elementary school \\
Junior high school \\
High school \\
University \\
\end{tabular} & \begin{tabular}{|l|}
$7(5.5)$ \\
$55(43.7)$ \\
$19(15.1)$ \\
$19(15.1)$ \\
$26(20.6)$ \\
\end{tabular} & $\begin{array}{l}36.57 \pm 5.74 \\
28.38 \pm 8.80 \\
27.21 \pm 8.53 \\
24.78 \pm 8.80 \\
24.34 \pm 8.53 \\
\end{array}$ & $0.008^{*}$ & \begin{tabular}{|l|}
$13.00 \pm 2.51$ \\
$10.78 \pm 4.02$ \\
$9.84 \pm 4.12$ \\
$9.68 \pm 4.19$ \\
$9.23 \pm 4.89$ \\
\end{tabular} & 0.194 & $\begin{array}{l}5.42 \pm 2.63 \\
4.63 \pm 2.14 \\
4.21 \pm 1.71 \\
4.00 \pm 2.30 \\
3.61 \pm 2.75 \\
\end{array}$ & 0.158 \\
\hline \multicolumn{8}{|l|}{ Profession } \\
\hline $\begin{array}{l}\text { Housewife } \\
\text { Officer } \\
\text { A retired } \\
\text { Workers } \\
\text { Freelancer } \\
\text { Student }\end{array}$ & $\begin{array}{l}29(23.1) \\
18(14.3) \\
42(33.3) \\
9(7.1) \\
27(21.4) \\
1(0.8)\end{array}$ & \begin{tabular}{|l}
$31.72 \pm 7.83$ \\
$25.05 \pm 9.32$ \\
$26.88 \pm 7.83$ \\
$24.55 \pm 11.14$ \\
$25.62 \pm 7.53$ \\
25.00
\end{tabular} & $0.027^{*}$ & \begin{tabular}{|l}
$12.44 \pm 3.69$ \\
$9.50 \pm 3.32$ \\
$10.59 \pm 3.52$ \\
$8.55 \pm 4.44$ \\
$8.66 \pm 4.15$ \\
7.00
\end{tabular} & $0.016^{*}$ & $\begin{array}{l}5.31 \pm 2.07 \\
4.44 \pm 2.99 \\
3.78 \pm 2.01 \\
4.55 \pm 3.28 \\
3.96 \pm 1.78 \\
2.00\end{array}$ & 0.068 \\
\hline \multicolumn{8}{|l|}{ Chronic diseases } \\
\hline $\begin{array}{l}\text { Hypertension } \\
\text { Diabetes Mellitus } \\
\text { Diabetes Mellitus and Hypertension } \\
\text { Other } \\
\text { No }\end{array}$ & $\begin{array}{l}36(28.6) \\
13(10.3) \\
23(18.3) \\
11(8.7) \\
43(34.1)\end{array}$ & $\begin{array}{l}28.05 \pm 7.63 \\
21.61 \pm 5.73 \\
31.56 \pm 8.67 \\
27.90 \pm 10.08 \\
25.90 \pm 8.36\end{array}$ & $0.010^{*}$ & \begin{tabular}{|l}
$9.44 \pm 4.22$ \\
$9.00 \pm 4.16$ \\
$11.6 \pm 3.93$ \\
$11.63 \pm 4.78$ \\
$10.32 \pm 4.15$
\end{tabular} & 0.22 & $\begin{array}{l}4.33 \pm 2.37 \\
3.61 \pm 2.36 \\
4.65 \pm 2.40 \\
5.09 \pm 2.42 \\
4.11 \pm 2.12\end{array}$ & 0.572 \\
\hline \multicolumn{8}{|l|}{ Planned surgery } \\
\hline $\begin{array}{l}\text { CABG } \\
\text { VS } \\
\text { CABG+VS }\end{array}$ & $\begin{array}{l}73(57.9) \\
47(37.3) \\
6(4.8)\end{array}$ & $\begin{array}{l}26.68 \pm 8.22 \\
27.72 \pm 9.11 \\
31.16 \pm 7.30\end{array}$ & 0.438 & $\begin{array}{c}10.06 \pm 4.30 \\
10.76 \pm 4.01 \\
9.00 \pm 5.17\end{array}$ & 0.487 & $\begin{array}{l}4.06 \pm 2.25 \\
4.68 \pm 2.25 \\
4.33 \pm 3.14\end{array}$ & 0.289 \\
\hline Total & & $27.28 \pm 8.48$ & & $10.27 \pm 4.23$ & & $4.30 \pm 2.29$ & \\
\hline
\end{tabular}

CABG: Coronary Artery Bypass Surgery, VS: Valve Surgery * $p<0.05$

Table 2. The Relationship between Anxiety Specific to Surgery Questionnaire, Postoperative Numerical Pain Scale and Pittsburgh Sleep Quality Index Mean Rates $(n=126)$

\begin{tabular}{|l|l|}
\hline Variable & $\begin{array}{l}\text { Anxiety Specific to } \\
\text { Surgery Mean }\end{array}$ \\
\hline The Mean of Numeric Pain Scale Scores & r: 0.318 \\
p: $0.000^{*}$
\end{tabular}

${ }^{*} p<0.05$

Table 3. Perioperative Pittsburgh Sleep Quality Index Scores (PSQI) of Patients with Anxiety Specific to Surgery Questionnaire Means

\begin{tabular}{|l|l|l|l|}
\hline PSQI Score & $\begin{array}{l}\text { Number } \\
\text { (Percent) }\end{array}$ & $\begin{array}{l}\text { ASSQ } \\
\bar{x} \pm S D\end{array}$ & $\mathbf{p}$ \\
\hline $\begin{array}{l}\mathbf{5} \text { scores and } \\
\text { above }\end{array}$ & $\mathbf{1 1 8 ( 9 3 . 7 )}$ & $27.37 \pm 8.56$ & $0.814^{*}$ \\
\hline $\mathbf{0 - 4}$ scores & $8(6.3)$ & $26.00 \pm 7.55$ & \\
\hline
\end{tabular}

${ }^{*} p>0.05$

\section{DISCUSSION}

In our research, patient anxiety was determined to be at a moderate level (27.28 \pm 8.48$)$. An examination studies mentioned herein reveal that a moderate level of anxiety is commonly experienced by patients scheduled for OHS. In one study preoperative anxiety levels were found to be \%55 (41). Whether a surgery is planned or conducted as an emergency intervention also impacts the patients' preoperative anxiety levels. Karancı and Dirik (2003) found that the ASSQ scores of patients who underwent emergency surgery to be $27.54 \pm 8.95$ (37). Fındık and Yıldızeli Topçu (2012) included sample patients from urology, emergency and general surgery departments in their research study which examined the effect of type of surgical procedure on preoperative patient anxiety levels; the study found that mean ASSQ scores of patients who underwent a planned surgery to be $23.76 \pm 7.12$ (42). Although OHS is a planned surgery, the mean ASSQ scores of patients in this study were found to be $27.28 \pm 8.48$, similar to those of Karancı and Dirik (2003). This outcome can 
be interpreted as a sign that anxiety levels are higher in OHS patients compared to general surgery and urology patients; this may be attributable to the heart being a vital organ and so patients may feel the fear of death more acutely.

In this study, a difference based on gender and profession was found among patient's ASSQ scores, and female anxiety levels, especially those of housewives, were seen to be higher. Additionally, differentiation of anxiety scores based on educational level was found to stem from the literate group. Yılmaz et al. (2011) also reported a difference between preoperative anxiety scores in terms of gender and the educational level, for those patients scheduled to undergo cardiac surgery (43). The level of anxiety was higher in women than in men, and this may be associated with their roles and responsibilities; women find it easier to express their concerns than men due to the structure of Turkish society in general, wherein men feel as if they have to portray themselves as strong. Consequently, it is more difficult for men to express their feelings even express any feeling of anxiety. Conversely, several other studies indicate no difference in the levels of anxiety according to sex (44).

When the patient's ASSQ scores were examined, the highest score of questionnaire was observed to be given to the thought of overcoming postoperative pain and discomforts. The mean fear of postoperative pain and death scores were shown to be the greatest causes of causes of preoperative anxiety. These two results show a similarity with another study result, namely, the relationship between preoperative anxiety and postoperative pain. Similarly, Rosiek et al. (2016) detected anxieties in patients related to cardiac surgery, pain, postoperative complications and anesthesia prior to their OHS procedure (41). Other studies conducted in the field support the results the current study, emphasizing pain, sense of discomfort and fear of death as the most frequently encountered causes of preoperative anxiety (45).

Patient's mean score for death-related anxiety was moderate. During the research, patients had activity intolerance and dyspnea. Many coronary artery disease patients in particular had a recent acute myocardial infarction history. In this study patients may have become less sensitive to death due their history regarding myocardial infarction; they stated that they thought surgery to be a cure. Conversely, heart valve patients state that they never think of death and thought their OHS surgery to be a salvation since as disease prevents them from completing many daily activities. It was observed that frequent visits made by the surgeon to the patient, providing information related to surgery, relieved patients and increased their trust in the physician, thereby decreasing anxiety. Researchers conducted on this subject have drawn attention to the fact that patients who received preoperative information and education show lower degrees of anxiety and thus fewer related complications (35).

In this study, patients were reported moderate levels of pain (4.30 \pm 2.29$)$ after surgery. Khan et al. (2012) detected patients' mean pain scores to be 4.26 , 48-hours after surgery (27). Mathai and Sams (2015) detected that $68 \%$ of the patients who underwent cardiac surgery experienced mid-level pain (46). Mirbagher Ajorpaz et al. (2014) determined patients' mean postoperative pain scores to be $6.32 \pm 0.21$ (47). Pain scores in this study were lower than that of existing literature; this is potentially attributable to difficulties patient's ability to describe their pain. Patients might perceive postsurgical pain as a normal condition and refrain from expressing their true coping level.

In our study a statistically weak, positive and significant relation was detected between preoperative ASSQ scores and postoperative NPS scores $(r=0.318, p<0.05)$; as preoperative anxiety increases, so does the patients' postoperative pain. Sidar, Dedeli and Iskesen (2013) examined the relationship between anxiety and pain and determined that anxiety plays a particular and significant role in pain perception (36). Khan et al. (2012) examined pre - and postoperative pain levels and detected a positive relationship between the two (27). The authors of the current study thought preoperative anxiety levels would increase the perception of pain caused by physiological effects. Besides, nurses and relatives of the patient are likely to visit them more regularly if they are experiencing higher levels of pain. It makes the patient feel more confident.

After OHS, sleep problems are frequently experienced, particularly by patients who remain in the hospital, sleep quality is considered very low $(10.27 \pm 4.23)$. The adverse effect of this on the circadian rhythm can result in increased anxiety levels to deterioration in patients' sleep patterns $(7,48)$. In our study $93.7 \%(n=118)$ of all individuals were found to have experienced poor sleep quality, though no relationship between preoperative anxiety and perioperative sleep quality was found. These outcomes suggest that sleep problems are caused by other factors. In corroboration with the findings of this study, Özkaya et al. (2013) stated that patients with high postoperative pain experienced significantly more severe sleep problems and found other factors causing sleep problems such as stuffiness in the room, medical devices attached to body, crowding in the room, and noise (49). In another study a compulsory supine sleeping position $(74.3 \%)$, pain $(47.1 \%)$ and disease-related anxiety (12.9\%) were included as factors effecting postoperative sleep in cardiac surgery patients (50).

\section{CONCLUSION}

The study concluded preoperative anxiety has a little bit impact on postoperative pain, but no effect on sleep quality for OHS patients. Pain remains a major problem influencing patients' recovery. In this study, patients had very bad sleep quality and so their circadian rhythms were affected. Health professionals have a key role to play to management of three enemies of circadian rhythm. They must investigate prevention methods for preoperative anxiety, postoperative pain and perioperative sleep problems for OHS patients. Nurses must collaborate the team and the role of patient advocacy must be foregrounded. 


\section{REFERENCES}

[1] Kocabaşoğlu N. An overview of anxiety disorders. Symposium series of frequent psychiatric diseases in Turkey 2008; 62:175184.

[2] Oz F. Anxiety problems. In: Gorman LM, Sultan DF. Öz F, Demiralp M, editors. Psychosocial Nursing. 3th ed. Ankara: Akademisyen Bookstore; 2014.

[3] Fitzsimons D, Parahoo K, Richardson SG, Stringer M. Patient anxiety while on a waiting list for coronary artery bypass surgery: a qualitative and quantitative analysis. Heart Lung 2003;32:23-31.

[4] Hoyer J, Eifert GH, Einsle F, Zimmermann K, Krauss S, Knaut M, Matschke K, Köllner V. Heart-focused anxiety before and after cardiac surgery. J Psychosom Res 2008; 64:291-297.

[5] Tully PJ, Baker RA. Depression, anxiety, and cardiac morbidity outcomes after coronary artery bypass surgery: a contemporary and practical review. J Geriatr Cardiol 2012; 9:197-208.

[6] Koivula M, Tarkka MT, Tarkka M, Laippala P, Paunonen-Ilmonen M. Fear and anxiety in patients at different time-points in the coronary artery bypass process Int J Nurs Stud 2002; 39:811-822.

[7] Coles ME, Schubert JR, Nota JA. Sleep, circadian rhythms, and anxious traits. Curr Psychiat Rep 2015; 17(9):73.

[8] Parvan K, Zamanzadeh V, Dizaji SL, Shabestari MM, Safaie N. Patient's perception of stressors associated with coronary artery bypass surgery. J Cardiovasc Thorac Res 2013; 5(3):113117.

[9] Takagi H, Ando T, Umemoto T. Perioperative depression or anxiety and postoperative mortality in cardiac surgery: a systematic review and meta-analysis. Heart Vessels 2017; 32(12):1458-1468.

[10] Ozpelit ME, Ozpelit E, Dogan NB, Pekel N, Ozyurtlu F, Yilmaz A, Saygi S, Tengiz I, Ercan E. Impact of anxiety level on circadian rhythm of blood pressure in hypertensive patients. Int J Clin Exp Med 2015; 8(9):16252-16258.

[11] Cserép Z, Losoncz E, Balog P, Szili-Török T, Husz A, Juhász B, Kertai MD, Gál J, Székely A. The impact of preoperative anxiety and education level on long-term mortality after cardiac surgery. J Cardiothorac Surg 2012; 7:86.

[12] Douki ZE, Vaezzadeh N, Shahmohammadi S, Shahhosseini Z, Tabary SZ, Mohammadpour RA, Esmaeeli M. Anxiety before and after coronary artery bypass grafting surgery: relationship to QOL. Middle-East J. Sci. Res 2011; 7(1):103-108.

[13] Huang APS, Sakata RK. Pain after sternotomy-review. Rev Bras Anestesiol 2016; 66(4):395-401.

[14] Ziehm S, Rosendahl J, Barth J, Strauss BM, Mehnert A, Koranyi S. Psychological interventions for acute pain after open heart surgery. Cochrane Database Syst Rev 2017; 7: 1-3.

[15] Leegaard M, Naden D, Fagermoen MS. Postoperative pain and self-management: women's experiences after cardiac surgery. J Adv Nurs 2008; 63(5):476-485.

[16] Oderda G. Challenges in the management of acute postsurgical pain. Pharmacotherapy. 2012; 32(9):6-11.

[17] Khalkhali H, Tanha ZER, Feizi A, Ardabili SS. Effect of applying cold gel pack on the pain associated with deep breathing and coughing after open heart surgery. Iran J Nurs Midwifery Res 2014; 19(6):545-549.

[18] Bjørnnes AK, Rustøen R, Lie I, Watt-Watson J, Leegaard M. Pain characteristics and analgesic intakebefore and following cardiac surgery. Eur J Cardiovasc Nurs 2016; 15(1):47-54.
[19] Mello LC, Rosatti SFC, Hortense P. Assessment of pain during rest and during activities in the postoperative period of cardiac surgery. Rev Lat Am Enfermagem 2014; 22(1):136-143.

[20] Parizad R, Abdolahzadeh F, Mousavi-Shabestari M. Pain after cardiac surgery: a review of the assessment and management. Crescent J Med Biol Sci 2014; 1(4):113-117.

[21] Öztürk OM, Uluşahin A. Mental health and disorders. 13th ed. Ankara: Tuna Printing; 2015.

[22] Little A, Ethier C, Ayas N, Thanachayanont T, Jiang D, Mehta $\mathrm{S}$. A patient survey of sleep quality in the intensive care unit. Minerva Anestesiol 2012; 78(4): 406-414.

[23] Le Grandea MR, Jacksona AC, Murphya BM, Thomason N. Relationship between sleep disturbance, depression and anxiety in the 12 months following a cardiac event. Psychol Health Med 2016; 21(1): 52-59.

[24] Pröpper J, Van Valen R, Van Domburg RT, Brunott M, Bogers AJJC. Quality of sleep at the ward after cardiothoracic surgery. Open Journal of Nursing 2015; 5:529-537.

[25] Yang PL, Huang GS, Tsai CS, Lou MF. Sleep quality and emotional correlates in taiwanese coronary artery bypass graft patients 1 week and 1 month after hospital discharge: a repeated descriptive correlational study. Plos One 2015; 10(8):e0136431.

[26] Akıncı E, Orhan FÖ. Circadian rhythm sleep disorders. Current Approaches in Psychiatry 2016; 8(2):178-189.

[27] Khan, RS, Skapinakis P, Ahmed K, Stefanou DC, Ashrafia H, Darzi A, Athanasiou T. The association between preoperative pain catastrophizing and postoperative pain Intensity in cardiac surgery patients. Pain Med 2012; 13(6):820-827.

[28] Matthews EE. Sleep disturbances and fatigue in critically ill patients. AACN Adv Critical Care 2012; 22(3):204-224.

[29] Engwall M, Fridh I, Johansson L, Bergbom I, Lindahl B. Lighting, sleep and circadian rhythm: An intervention study in the intensive care unit. Intensive Crit Care Nurs 2015; 31(6):325335.

[30] Elliott R, Rai T, McKinley S. Factors affecting sleep in the critically ill: an observational study. J Crit Care 2014; 29(5):859-863.

[31] Arita H, Takeno Y, Fujimoto E. Sleep disturbance in elderly patients after cardiac surgery during their stay in intensive care unit and surgical ward. J Nurs Care 2013; 3:137.

[32] Kamalipour H, Vafaei A, Kazemi AP, Khademi S. Comparing the prevalence of chronic pain after sternotomy in patients undergoing coronary artery bypass grafting using the internal mammary artery and other open heart surgeries. Anesth Pain Med 2014; 4(3):e17969.

[33] Hedges C, Redeker NS. Comparison of sleep and mood in patients after on-pump and off-pump coronary artery bypass surgery. Am J Crit Care 2008; 17(2):133-140.

[34] Akinci B, Yeldan I, Bayramoglu Z, Akpinar TB. The effects of posture and relaxation training on sleep, dyspnoea, pain and, quality of life in the short-term after cardiac surgery: a pilot study. Turk Gogus Kalp Dama 2016; 24(2):258-265.

[35] Guo P, East L, Arthur A. A preoperative education intervention to reduce anxiety and improve recovery among Chinese cardiac patients: a randomized controlled trial. Int J Nurs Stud 2012; 9(2):129-137.

[36] Sidar A, Dedeli Ö, İskesen Ai. The relationship between anxiety, pain distress and pain severity before and after open heart surgery in patients. J Turk Soc Intens Care 2013; 4:1-8. 
[37] Karancl AN, Dirik G. Predictors of pre and postoperative anxiety in emergency surgery patients. J Psychosom Res 2003; 55(4):363-369.

[38] Eti Aslan F, Öztürk Z. Nature and control of pain. 23th ed. Ankara: Akademisyen Bookstore; 2014.

[39] Buysse DJ, Reynolds CF, Monk TH, Berman SR, Kupher DJ. The pittsburgh sleep quality index: a new instrument for psychiatric practice and research. Psychiatry Res 1989; 28(2):193-213

[40] Agargün YM, Kara H, Anlar O. The reliability and validity of turkish version of pittsburgh sleep quality index. Turk Psikiyatri Derg 1996;7:107-115.

[41] Rosiek A, Kornatowski T, Rosiek-Kryszewska A, Leksowski L, Leksowski K. Evaluation of stress intensity and anxiety level in preoperative period of cardiac patients. Biomed Res Int 2016; 1-8.

[42] Fındık ÜY, Yıldızeli Topçu S. Effect of the way of surgery on preoperative anxiety. Hacettepe University Faculty of Health Sciences Nursing Journal 2012;19(2):22-33.

[43] Yilmaz M, Sezer H, Gürler H, Bekar M. Predictors of preoperative anxiety in surgical inpatients. J Clin Nurs 2011; 21:956-964.

[44] Hernández-Palazón J, Fuentes-García D, Falcón-Araña L, RocaCalvo MJ, Burguillos-López S, Doménech-Asensi P, JaraRubio R. Assessment of preoperative anxiety in cardiac surgery patients lacking a history of anxiety: contributing factors and postoperative morbidity. J Cardiothorac Vasc Anesth 2018; 32(1):236-244.

[45] Feuchtinger J, Burbaum C, Heilmann C, Imbery C, Siepe M, Stotz U, Fritzsche K, Beyersdorf F. Anxiety and fear in patients with short waiting times before coronary artery bypass surgery - a qualitative study. J Clin Nurs 2014; 23(13-14):1900-1907.

[46] Mathai AT, Sams LM. Assessment of quality of pain and contributing factors affecting level of pain among patients who had undergone cardiac surgery in selected hospitals, Mangalore. Asian Pac IsI Nurs J 2015; 2(1):8-11.

[47] Ajorpaz NM, Mohammadi A, Najaran H, Khazaei S. Effect of music on postoperative pain in patients under open heart surgery. Nurs Midwifery Stud 2014; 3(3):e20213.

[48] Kamdar BB, Needham DM, Collop NA. Sleep deprivation in critical illness: its role in physical and psychological recovery. J Intensive Care Med 2012; 27(2):97-111.

[49] Odül Ozkaya B, Yüce Z, Gönen M, Gül A, Alis H. Factors affecting the sleep pattern of the patients in the early postoperative period. Medical Journal of Bakırkoy 2013; 9(3): 121-125.

[50] Liao WC, Huang CY, Huang TY, Hwang SL. A systematic review of sleep patterns and factors that disturb sleep after heart surgery. J Nurs Res 2011; 19(4): 275-288.

How to cite this article: Kankaya E. A., Bilik O. Three Enemies of Circadian Rhythm: Anxiety, Sleeplessness and Pain in Patients Following Open-Heart Surgery. Clin Exp Health Sci 2019; 9: 246-252. DOI: 10.33808/clinexphealthsci.599805 